\title{
Efficacy of MS-275, a selective inhibitor of class I histone deacetylases, in human colon cancer models
}

\author{
TOMKE UTE BRACKER ${ }^{1}$, ANETTE SOMMER ${ }^{2}$, IDUNA FICHTNER ${ }^{3}$, \\ HORTENSIA FAUS $^{1}$, BERNARD HAENDLER ${ }^{1}$ and HOLGER HESS-STUMPP ${ }^{1}$ \\ ${ }^{1}$ Global Drug Discovery, Therapeutic Research Group Oncology, and ${ }^{2}$ Global Drug Discovery, \\ Target Discovery, Bayer Schering Pharma AG, 178 Müllerstr., 13353 Berlin; ${ }^{3}$ Max-Delbrück \\ Center for Molecular Medicine, 10 Robert-Rössle-Str., 13125 Berlin-Buch, Germany
}

Received April 1, 2009; Accepted June 11, 2009

DOI: 10.3892/ijo_00000406

\begin{abstract}
N-(2-aminophenyl)-4-[N-(pyridine-3yl-methoxycarbonyl) aminomethyl] benzamide (MS-275) is a second generation histone deacetylase (HDAC) inhibitor with significant anti-tumor efficacy currently in clinical development. We investigated the effect of MS-275 treatment on various colon cancer cell lines, as well as on mouse xenograft models derived from human colorectal cancer. MS-275 exerted strong anti-proliferative effects in five cell lines and increased the acetylation of histones 3 and 4 . In vivo testing of the compound in eight different models of human colon cancer derived from primary colorectal cancers or from established cell lines revealed that five models were responders, two non-responders and one an anti-responder. Gene expression profiles were determined in order to identify genes and pathways differentially regulated upon MS-275 treatment in responder versus non-responder models. Principle component analysis revealed a correlation of the anti-tumor efficacy with the sub-clustering of the MS-275 treatment groups in 7 out of 8 models. Although the overall gene expression pattern was rather unique for each individual model, 129 genes were significantly up- and 58 genes significantly down-regulated in at least 2 out of 5 responder models in response to MS-275 treatment. We identified potential biomarkers for response to MS-275, such as PRA1, MYADM and PALM2-AKAP2 which were up-regulated in all responder models and downregulated or unchanged in all non-responder models. Our results provide a starting point for the development of clinically relevant biomarkers for predicting a response to MS-275 and the understanding of the mode of action of this HDAC inhibitor.
\end{abstract}

Correspondence to: Dr Bernard Haendler, TRG Oncology, Bayer Schering Pharma AG, 178 Müllerstr., D-13353 Berlin, Germany

E-mail: bernard.haendler@bayerhealthcare.com

Key words: colon cancer, chromatin, gene expression, histone deacetylase inhibitor, biomarker

\section{Introduction}

In recent years it has become clear that deregulation of epigenetic processes plays a major role in tumorigenesis (1-5). The term epigenetics relates to changes in gene expression elicited by modifications of histone marks such as acetylation or methylation as well as of DNA methylation, all of which do not alter the DNA sequence (6-11). These modifications may be transmitted over generations or be of more transient nature.

Local modification of histone acetylation is an important factor regulating the access of transcription factors to DNA $(5,7,10)$. This is controlled by histone acetyltransferases and histone deacetylases (HDACs), and plays an important role for normal cellular functions including regulation of cell cycle progression, differentiation and apoptosis (12-14). The abnormal activity of these key modulators of chromatin structure may be associated with the development of a malignant phenotype. Indeed, overexpression of HDACs as well as aberrant recruitment to promoters leading to condensation of chromatin and to silencing of tumor suppressor genes has been reported in several cancer types (12-15).

The inhibition of HDAC activity results in the hyperacetylation of the tails of histone $3(\mathrm{H} 3)$ and histone $4(\mathrm{H} 4)$. This facilitates the relaxation of the chromatin structure and allows the re-expression of silenced genes, including p21 (16-21). In addition, several genes are repressed following HDAC inhibition and, intriguingly, the number of downregulated genes may be as high as that of up-regulated ones (22). Generally, pro-apoptotic and anti-proliferative genes show increased expression after HDAC inhibitor treatment whereas anti-apoptotic and pro-growth genes are downregulated (23-25). Furthermore, direct acetylation and regulation of transcription factors such as p53, STAT1 or steroid receptors leading to modifications in gene expression patterns also account for some of the effects of HDAC inhibitors $(26,27)$. A third mechanism of action not directly linked to gene regulation has been evidenced. It involves the direct acetylation of non-transcriptional targets such as HSP90, tubulin or Ku70 (26).

HDAC inhibitors represent a structurally diverse group of compounds. Most, like suberoylanilide hydroxamic acid 
(SAHA) and trichostatin A (TSA) inhibit the activity of many if not all HDACs (28-34). N-(2-aminophenyl)-4-[N(pyridine-3yl-methoxy-carbonyl) aminomethyl] benzamide (MS-275) has a much more restricted profile (28,35-37). Several studies indicate that MS-275 is a selective inhibitor of HDAC1 and HDAC2, with $\mathrm{IC}_{50}$ values in the sub-micromolar range $(28,31,32)$. The compound shows significant antitumor efficacy in vitro and in vivo and is currently in phase I/II clinical trials (35).

In the current study, we investigated the efficacy of MS275 in human colon cancer models in vitro and in vivo. A large number of colorectal cancers show, in addition to genetic alterations such as p53 and $\beta$-catenin mutations, epigenetic abnormalities such as changes in DNA methylation and in histone modification pattern (38). Also, overexpression of HDAC2 has frequently been observed in colon cancers (39). We first determined the effects of MS-275 on the proliferation of colon cancer cell lines and analyzed pharmacodynamic markers. We then treated tumors grown as xenografts from eight different human colon cancer models with MS275 and determined gene expression profiles. Since not all models showed a significant tumor inhibition upon treatment, the comparison of these expression profiles may represent the basis to learn more about the mode of action of MS-275 and to find markers that may help to distinguish between responders and non-responders to treatment.

\section{Material and methods}

Cell culture and reagents. Human colon carcinoma cell lines Colo205, HCT116, HT29, LoVo and SW480 were purchased from the American Type Culture Collection (Bethesda, MD, USA) or the German Collection of Microorganisms and Cell Cultures (Braunschweig, Germany) and cultured according to the guidelines. For immunoblot analysis, cells were treated with 0.3 or $3 \mu \mathrm{M}$ MS-275 (Bayer Schering Pharma AG, Berlin, Germany) for 24,48 or $72 \mathrm{~h}$. Cells were rinsed with PBS and centrifuged at $1200 \mathrm{x} g$ for $5 \mathrm{~min}$. Total protein extracts were prepared using the M-PER reagent (Perbio, Bonn, Germany) and protein concentrations were determined with the BCA-Assay (Perbio).

SDS-PAGE and immunoblotting. For SDS-polyacrylamide gel electrophoresis (PAGE), total protein extracts were prepared in sample buffer $(4 \mathrm{x}$ LDS sample buffer, $10 \mathrm{x}$ reducing agent), heated at $95^{\circ} \mathrm{C}$ for $5 \mathrm{~min}$ and loaded onto 4-12\% NuPAGE Bis-Tris gels. After electrophoresis, proteins were transferred to polyvinylidene difluoride membranes (all accessories and buffers for PAGE were purchased from Invitrogen, San Diego, CA, USA) and blocked in 5\% skimmed milk in TBS containing $0.1 \%$ Tween-20 (TBST) for $30 \mathrm{~min}$. The following primary antibodies were diluted in 5\% skimmed milk in TBST: anti-p21 (1:200; Santa Cruz Biotechnology, Santa Cruz, CA, USA); anti-acetylated histone 3 and histone 4 (1:2000 and 1:20000, respectively; Upstate, Chemicon, Hampshire, UK); anti-HDAC2 (1:2000; Abcam, Cambridge, UK); anti-GAPDH (1:5000; Zytomed Systems, Berlin, Germany), and incubated overnight at $4^{\circ} \mathrm{C}$. Membranes were washed three times with TBST and incubated with horseradish peroxidase-conjugated anti-mouse or anti-rabbit antibodies (1:10000 in 5\% skimmed milk in TBST, Dianova, Hamburg, Germany) for $45 \mathrm{~min}$ at room temperature. Before chemiluminescence detection (ECL plus, GE Healthcare, Munich, Germany) membranes were washed three times with TBST.

Proliferation assay. After trypsinization, cells were seeded in 96-well plates at 10,000-30,000 cells per well, depending on growth properties, and allowed to adhere overnight. MS-275, dissolved in DMSO and diluted in medium, was added at different concentrations ranging from 0.001 to $10 \mu \mathrm{M}$. After $72 \mathrm{~h}$ the medium was replaced with $30 \%$ Alamar Blue solution (diluted in medium; Invitrogen) and the cells were incubated for $4 \mathrm{~h}$ at $37^{\circ} \mathrm{C}\left(80 \%\right.$ humidity, $95 / 5 \%$ air/ $\left.\mathrm{CO}_{2}\right)$. Inhibition of proliferation was detected colorimetrically by measuring the excitation at $590 \mathrm{~nm}$ and plotting it against MS-275 concentration. The $\mathrm{IC}_{50}$ values were calculated using these graphs.

Gene expression knock-down experiments. For small interfering RNA (siRNA) silencing of HDAC2, a predesigned siRNA pool and the non-targeting siCONTROL siRNA pool was used (Dharmacon, Perbio). HCT116 cells were seeded at a concentration of 1000 cells per well in a 96-well plate and transfected with $20 \mathrm{nM}$ siRNA using the HiPerFect transfection reagent (Qiagen, Hilden, Germany) according to the manufacturer's guidelines. Twenty-four hours after transfection, different concentrations of MS-275, ranging from 0.001 to $10 \mu \mathrm{M}$, were added to the cells. Proliferation was assessed with the Alamar Blue assay after $72 \mathrm{~h}$ of MS-275 treatment. For validation of HDAC2 knock-down efficiency and viability of the cells, $10^{5}$ cells were seeded in a 24 -well plate and transfected with $20 \mathrm{nM}$ siRNA. RNA and proteins were isolated from the same well using the AllPrep RNA/ Protein Kit (Qiagen) according to the standard protocol. HDAC2 knock-down efficiency was measured by quantitative real-time polymerase chain reaction (PCR) and immunoblotting.

Animal experiments. For tumor xenograft experiments, 6-weekold female nude mice (NMRI-nu/nu) were utilized. HCT116 cells $\left(1.5 \times 10^{6}\right)$, HT29 cells $\left(1 \times 10^{6}\right)$ and LoVo cells $\left(1.5 \times 10^{6}\right)$ were mixed with matrigel (BD Biosciences, Heidelberg, Germany) and injected subcutaneously into one flank. Human colon carcinoma tissue was obtained from primary tumors (Co5854, Co5776 and Co5676) or liver metastases of colon cancer (Co5841 and Co6044). Tumor fragments (2-3 $\left.\mathrm{mm}^{3}\right)$ were transplanted onto the flanks of anaesthetized nude mice. Primary xenograft models were established at the MaxDelbrück-Center for Molecular Medicine, Berlin, Germany (40). After the tumors became palpable, MS-275 treatment was initiated. The mice received a daily oral dose of 0,10 or $40 \mathrm{mg} / \mathrm{kg}$ MS-275. Irinotecan (Campto ${ }^{\circledR}$, Pfizer, Karlsruhe, Germany) was used as a positive control substance and given intraperitoneally at a daily dose of $15 \mathrm{mg} / \mathrm{kg}$. The diameter of the tumors was measured twice weekly with a caliper and tumor volumes were calculated by the formula: (width ${ }^{2} \mathrm{x}$ length) $\times 0.5$. The median values of treated versus control (T/C) values of the groups were used to evaluate the therapeutic efficacy. 
A

\begin{tabular}{|c|c|c|c|c|c|c|c|c|c|}
\hline Cell line I & $\begin{array}{l}\mathrm{IC}_{50} \\
{[\mu \mathrm{M}]}\end{array}$ & \multicolumn{6}{|c|}{$0.3 \mu \mathrm{M}$ MS-275 } & \multicolumn{2}{|c|}{$3 \mu \mathrm{M}$ MS-275 } \\
\hline & & $\begin{array}{ccc} & \text { p21 } & \\
0 & 24 \quad 48 & 72 \\
\end{array}$ & $\begin{array}{l}\text { acetyl-H3 } \\
0 \quad 24 \quad 48 \quad 72 \\
\end{array}$ & $\begin{array}{l}\text { acetyl-H4 } \\
0 \quad 24 \quad 48 \quad 72\end{array}$ & $\begin{array}{l}\text { HDAC1 } \\
0 \quad 24 \quad 48 \quad 72\end{array}$ & $\begin{array}{l}\text { HDAC2 } \\
0 \quad 24 \quad 48 \quad 72\end{array}$ & $\begin{array}{l}\text { GAPDH } \\
0 \quad 24 \quad 4872\end{array}$ & $\begin{array}{c}\text { acetyl-H } \\
0 \quad 24 \\
\end{array}$ & $\begin{array}{c}\text { GAPDH } \\
024 \\
\end{array}$ \\
\hline LoVo & 0.45 & -1 & - & -- & & ---- & -- & - & 6 \\
\hline HCT116 0 & 0.51 & $-\infty$ & - & -2 & -- & --- & & 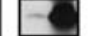 & $-\infty$ \\
\hline HT29 & 1.01 & 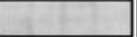 & - & $-\infty$ & --- & - - - & - - & - & ق \\
\hline SW480 1 & 1.45 & -- & - & - & & - & --- & $a$ & 0 \\
\hline Colo205 2 & 2.18 & & -- & -2 & --- & & & 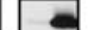 & 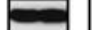 \\
\hline
\end{tabular}

B

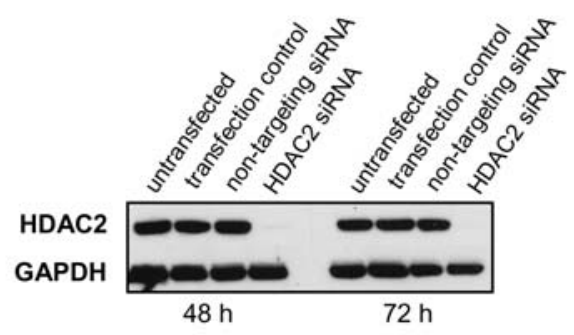

C

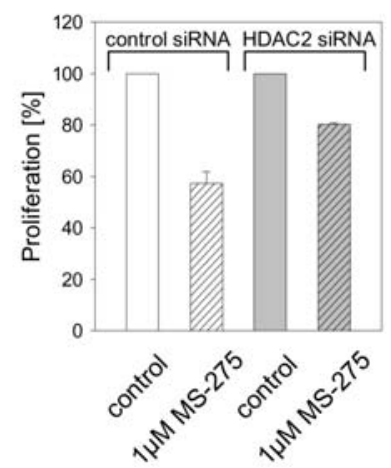

Figure 1. Analysis of MS-275 pharmacodynamic markers in colon cancer cell lines. (A) Immunoblotting analysis of p21 expression, of H3 and H4 acetylation, and of HDAC1 and HDAC2 levels after MS-275 treatment for the indicated timepoints (in hours). GAPDH levels were determined as controls. (B) Evaluation of HDAC2 protein down-regulation after siRNA treatment of HCT-116 cells for the indicated timepoints. (C) Impact of HDAC2 levels on the anti-proliferative effects of MS-275 on HCT116 cells.

RNA extraction. Tumor tissue was taken from sacrificed animals, snap-frozen and stored at $-80^{\circ} \mathrm{C}$ until use. Total RNA was extracted using the RNeasy mini kit (Qiagen) according to the manufacturer's recommendations including a DNase I (Qiagen) step to digest genomic DNA. The quality of total RNA was checked for integrity using the RNA LabChips on the Agilent Bioanalyzer 2100 (Agilent Technologies Inc., Palo Alto, CA, USA) and the concentration was determined on a Nanodrop spectrophotometer (Peqlab, Erlangen, Germany).

In vitro RNA transcription and hybridization to Affymetrix GeneChips. The One-Cycle Eukaryotic Target Labeling Kit (Affymetrix Inc., Santa Clara, CA, USA) was used according to the manufacturer's instructions. Briefly, $2 \mu \mathrm{g}$ of high quality total RNA were reverse-transcribed using a T7 tagged oligo-dT primer for the first-strand cDNA synthesis reaction. After RNase H-mediated second-strand cDNA synthesis, the double-stranded cDNA was purified and served as template for the subsequent in vitro transcription reaction which generates biotin-labeled complementary RNA (cRNA). The biotinylated cRNA was then cleaned up, fragmented and hybridized to GeneChip HGU133Plus2.0 expression arrays (Affymetrix), which contain 54675 probe sets. The GeneChips were washed and stained with streptavidin-phycoerythrin on a GeneChip Fluidics Station 450 (Affymetrix). After washing, the arrays were scanned on an Affymetrix Gene-Chip 3000 scanner with autoloader and barcode reader. A total of 169 HGU133Plus2.0 arrays were processed.

Data analysis. The quality of the hybridized arrays was analyzed with the Expressionist Pro 4.0 Refiner software
(Genedata, Basel, CH). The following analyses were performed, based on raw intensities of individual oligonucleotide features (probes): the experiments were grouped according to similarity and potential outlier experiments were removed (or selected for re-hybridization and/or refragmentation), the quality of a particular experiment was compared with a virtual reference experiment, which was computed as average of all feature intensities of all arrays in that group. Moreover, defects on the arrays were masked. Here, for each array, the spatial signal distribution was compared with the reference experiment of the experiment group it belonged to. Regions with sharp boundaries which had consistently higher or lower feature intensities compared to the reference experiment were flagged as defects and excluded from further analysis. In addition, a signal correction (distortion and gradient) was performed, the control gene statistics were calculated, and an overall classification of the quality of the experiments was provided.

The probe intensities on each array were summarized with the MAS5.0 summarization algorithm and the refined and summarized data were loaded into the CoBi database (Genedata). The analysis of the probeset-specific signal intensities was performed with the Expressionist Pro 4.0 Analyst software (Genedata). The data set was median normalized. Pathway analyses were performed with the GeneGo Metacore database and software tools.

Quantitative real-time RT-PCR. Aliquots of the total RNA from all tumors belonging to one treatment group were pooled and reverse-transcribed using the SuperScript III First-Strand Synthesis System for RT-PCR (Invitrogen) containing $3 \mu \mathrm{g}$ RNA, $5 \mathrm{ng} / \mu 1$ random hexamer primer and 


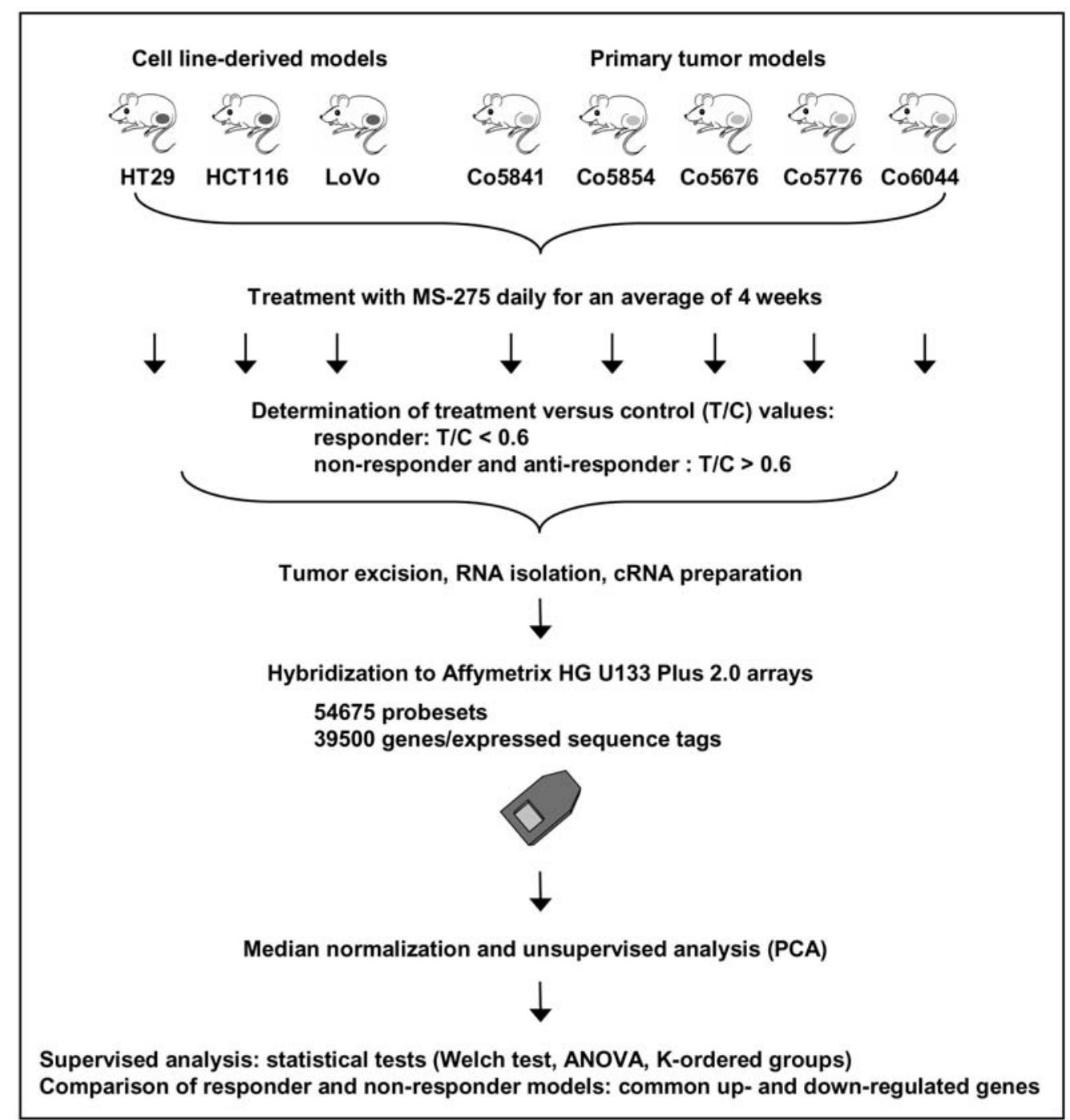

Figure 2. Experimental workflow for analysis of human colon cancer xenograft models. Eight different models were used for treatment with MS-275. The mice ( $\mathrm{N}=8$ per treatment group) were given vehicle control, 10 or $40 \mathrm{mg} / \mathrm{kg}$ of MS-275. RNA from individual tumors was isolated, cRNA was synthesized and hybridized to Affymetrix HGU133Plus2.0 arrays. The normalized dataset was subjected to unsupervised and supervised analyses with the Expressionist Pro 4.0 Analyst software.

$1 \mathrm{mM}$ deoxynucleotide triphosphate mix in a final volume of $20 \mu 1$. After an initial denaturation step at $65^{\circ} \mathrm{C}$ for $5 \mathrm{~min}$, the reverse transcriptase reaction was carried out at $25^{\circ} \mathrm{C}$ for $10 \mathrm{~min}, 50^{\circ} \mathrm{C}$ for $50 \mathrm{~min}$ and $85^{\circ} \mathrm{C}$ for $5 \mathrm{~min}$. Real-time PCR was carried out using predesigned TaqMan assays and TaqMan Fast Universal Master mix on an Applied Biosystems 7500 Fast Real-Time PCR System (Applied Biosystems Applera Deutschland GmbH, Darmstadt, Germany). Three genes were selected for quantitative real-time PCR analysis: prenylated rab acceptor 1 (PRA1, assay ID Hs00197506), myeloidassociated differentiation marker (MYADM, assay ID Hs00414763_m1) and paralemmin 2-A kinase anchor protein 2 (PALM2-AKAP2, assay ID HS00364914_m1). The levels of 18S rRNA transcripts (assay reference 4319413E) were determined as control. The real-time PCR reaction was performed in 96-well plates and contained $100 \mathrm{ng}$ cDNA, $12.5 \mu 12$ x TaqMan Fast Universal Master mix, $1.25 \mu 1$ TaqMan Assay Mix and 1.25 $\mu 1$ 18S rRNA primers/probe mix in a $25 \mu 1$ reaction mix. After an initial denaturation step at $95^{\circ} \mathrm{C}$ for $20 \mathrm{sec}, 40$ cycles consisting of denaturation at $95^{\circ} \mathrm{C}$ for $3 \mathrm{sec}$ and annealing at $60^{\circ} \mathrm{C}$ for $30 \mathrm{sec}$ were carried out. Triplicate values were determined for each sample.

The relative expression of each gene was determined on the basis of the comparative threshold cycle method $(\triangle \Delta \mathrm{CT}$ method). A standard curve was generated with $18 \mathrm{~S}$ rRNA in every real-time PCR run. Each CT value was normalized for the CT value of the 18S rRNA gene $(\triangle C T)$. Then, the normalized gene expression value of the calibrator (i.e., $\Delta \mathrm{CT}$ of the vehicle control group) was subtracted from the normalized target gene expression (i.e., $\Delta \mathrm{CT}$ of the MS-275 treatment groups) to obtain the $\Delta \Delta \mathrm{CT}$ value and the fold change of the gene in the treatment groups relative to the untreated control tumors was calculated.

\section{Results}

In vitro efficacy of $M S-275$. We assessed the antiproliferative effects of MS-275 on the five established colon cancer cell lines LoVo, HCT116, HT29, SW480 and Colo205 by determining cell numbers after a 3-day treatment. MS-275 

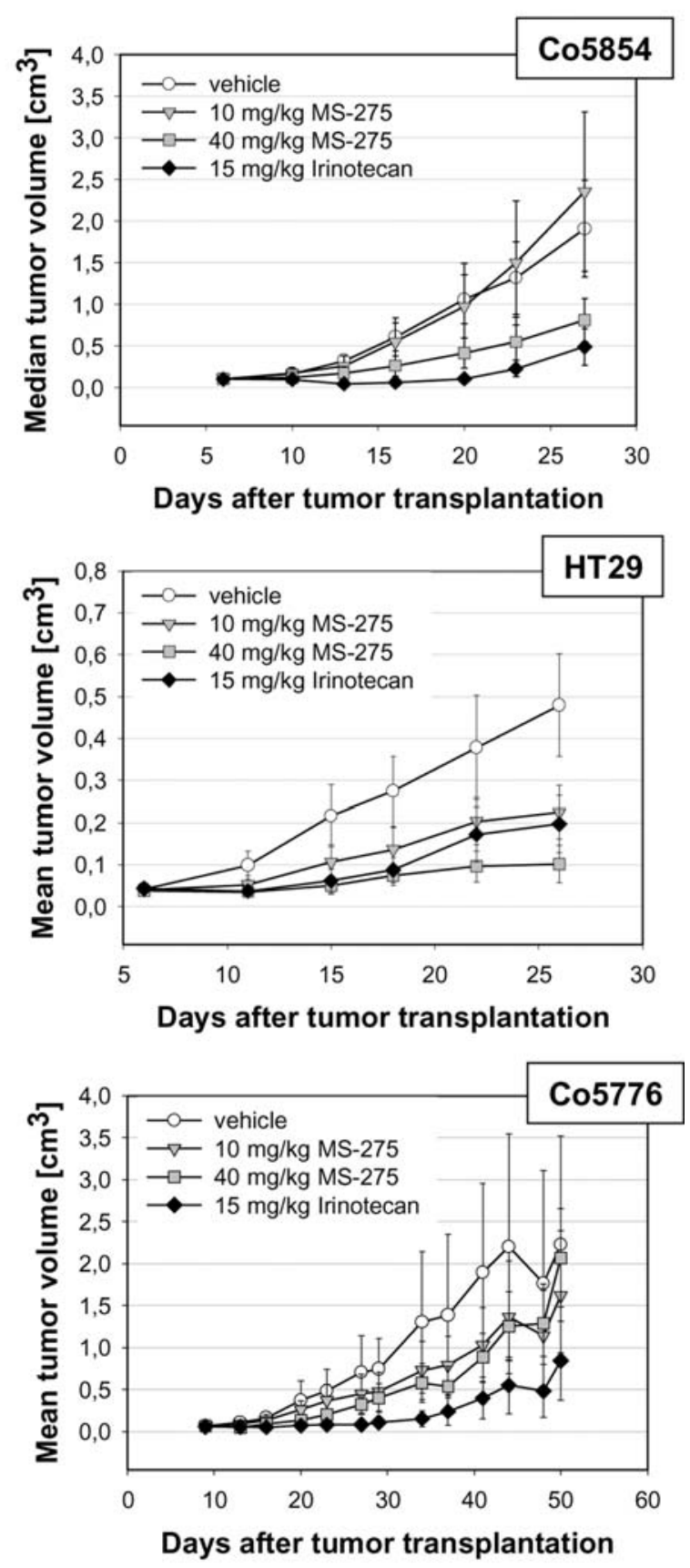

Figure 3. Efficacy of MS-275 on tumor growth in the responder models Co5854 and HT29, and in the non-responder model Co5776. Tumor volume was determined at the indicated timepoints. Irinotecan treatment was used as comparison.

inhibited all cell lines with $\mathrm{IC}_{50}$ values varying from 0.45 to $2.18 \mu \mathrm{M}$ (Fig. 1A). The treatment led to arrest in the $\mathrm{G}_{0} / \mathrm{G}_{1}$ phase and apoptosis (data not shown). We then tested the induction of the cyclin-dependent kinase inhibitor p21 which is induced upon treatment by several HDAC inhibitors and reflects the anti-proliferative effects of this compound class. We found that at a sub- $\mathrm{IC}_{50}$ concentration $(0.3 \mu \mathrm{M}), \mathrm{MS}-275$ induced p21 expression in LoVo, HCT116 and SW480 cells, whereas no such effect was detectable in HT29 and Colo205 cells (Fig. 1A). A 10-fold higher concentration of MS-275 induced p21 expression in Colo205, but not in HT29 cells (not shown). We then examined changes in histone ace- tylation. Stimulation of H3 acetylation was observed after 24-48 h in all cell lines, except in HT29 cells where it was observed only after $72 \mathrm{~h}$ of treatment. The amount of acetylated H3 was further increased when a higher MS-275 concentration $(3 \mu \mathrm{M})$ was used. An increase in $\mathrm{H} 4$ hyperacetylation was observed in all cell lines after $24 \mathrm{~h}$ of MS-275 treatment, albeit to different extents.

HDAC 1 and HDAC2 are the main targets of MS-275 (28,35-37). We therefore used immunoblotting to look at their expression levels in the different colon cancer cell lines (Fig. 1A). For HDAC1, very low basal levels were found. An induction was initially observed upon MS-275 treatment in HCT116, HT29 and Colo205 cells, followed by a decrease after $72 \mathrm{~h}$. LoVo and SW480 cells showed almost no expression of HDAC1. Thus, the HDAC1 protein levels did not correlate with the anti-proliferative activity of MS-275. Concerning HDAC2, we found that LoVo, HCT116 and HT29 cells strongly expressed it. SW480 and Colo205 had no detectable levels which were very slightly stimulated after MS-275 treatment. Thus, a higher HDAC2 expression level correlated with a high potency of MS-275.

In order to determine whether this finding had a functional relevance for MS-275 efficacy, we performed RNAi knockdown studies and subsequent proliferation assays in HCT116 cells. The HDAC2 mRNA level was dramatically reduced after siRNA transfection (not shown) and HDAC2 protein was no longer detectable, as assessed by immunoblotting (Fig. 1B). The down-regulation of HDAC2 was specific, as no reduction of HDAC1 mRNA or protein levels was seen (not shown). HDAC2 knock-down reduced the efficacy of MS-275 in proliferation assays. Only $20 \%$ growth inhibition was observed $72 \mathrm{~h}$ after $1 \mu \mathrm{M}$ MS-275 treatment in HCT-116 cells transfected with HDAC2-specific siRNAs compared to more than $40 \%$ in the control transfected cells (Fig. 1C). The respective $\mathrm{IC}_{50}$ values were 1.25 and $0.89 \mu \mathrm{M}$. Thus, knockdown of HDAC2 partly abrogated the anti-proliferative effect of MS-275, suggesting that this isoform was the relevant molecular target.

In vivo efficacy of $M S$-275. In order to better evaluate the therapeutic efficacy of MS-275 in colon cancer, different primary tumor models (Co5854, Co5676 and Co5776), two metastasis models (Co5841 and Co6044), as well as three xenograft models derived from the cell lines that responded best to MS-275 treatment (HCT116, HT29 and LoVo) were tested (Fig. 2). Tumor-bearing mice were treated with 0,10 or $40 \mathrm{mg} / \mathrm{kg}$ MS-275 once daily, and the tumor volumes were measured twice weekly. The growth curves observed for three tumors (Co5854, HT29 and Co5776) after MS-275 treatment are depicted, in comparison to irinotecan treatment (Fig. 3). The anti-tumor efficacy of MS-275 given daily at a $40 \mathrm{mg} / \mathrm{kg}$ concentration to treat the different colon cancer models is shown in Table I. The growth of 5 out of 8 models was significantly inhibited, as the tumor volume ratio between treated and control mice (T/C) was below 0.6 (i.e., $40 \%$ tumor growth inhibition). Two models were classified as non-responders with $\mathrm{T} / \mathrm{C}$ values of 0.7 and 1.22 (Co5841 and Co5776, respectively). The LoVo model grew faster than the control following MS-275 treatment (T/C value of 2.04) leading to its classification as an anti-responder. Thus, this 


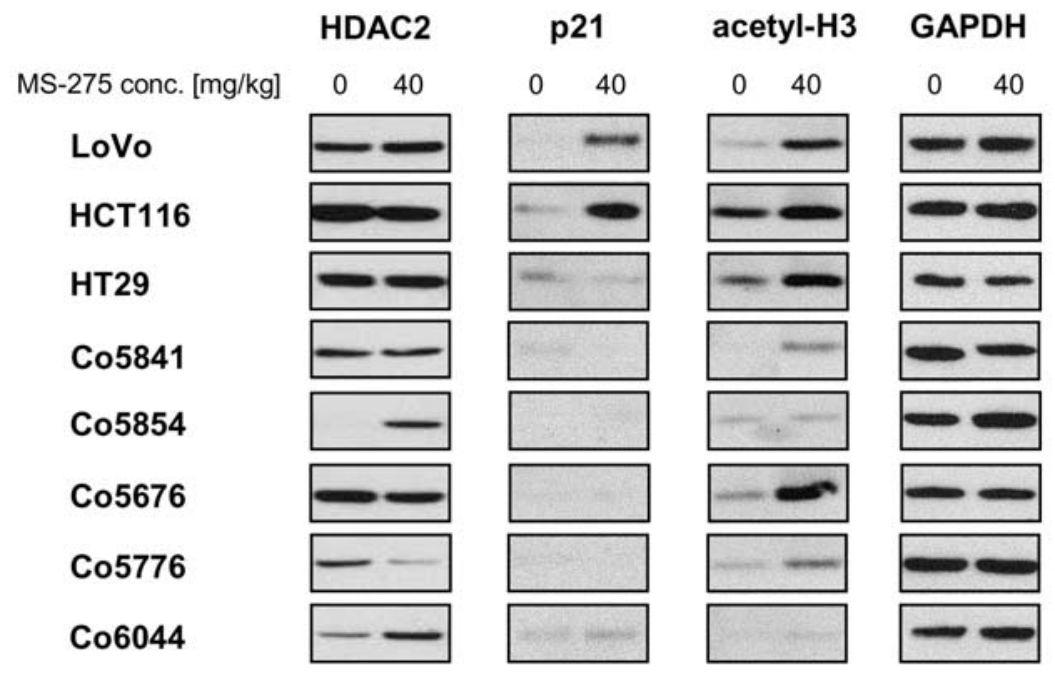

Figure 4. Analysis of pharmacodynamic markers in vivo. Tumors were treated with $40 \mathrm{mg} / \mathrm{kg}$ MS-275 and analyzed by immunoblotting for their levels of HDAC2, p21 and acetylated $\mathrm{H} 3$ at the end of the study. GAPDH levels were determined as controls.

A

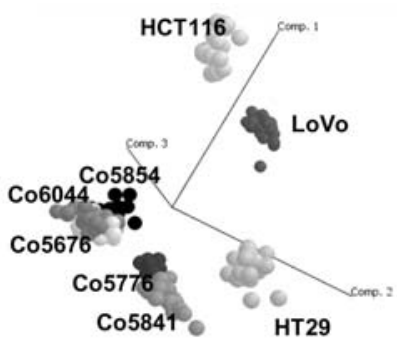

B

Responder

$\begin{array}{cc}\begin{array}{l}\text { In vivo efficacy } \\ \text { of MS-275 }\end{array} & \begin{array}{c}\text { Sub-clustering of } \\ \text { treatment groups (PCA) }\end{array}\end{array}$

Non-responder

In vivo efficacy Sub-clustering of

of MS-275 treatment groups (PCA)
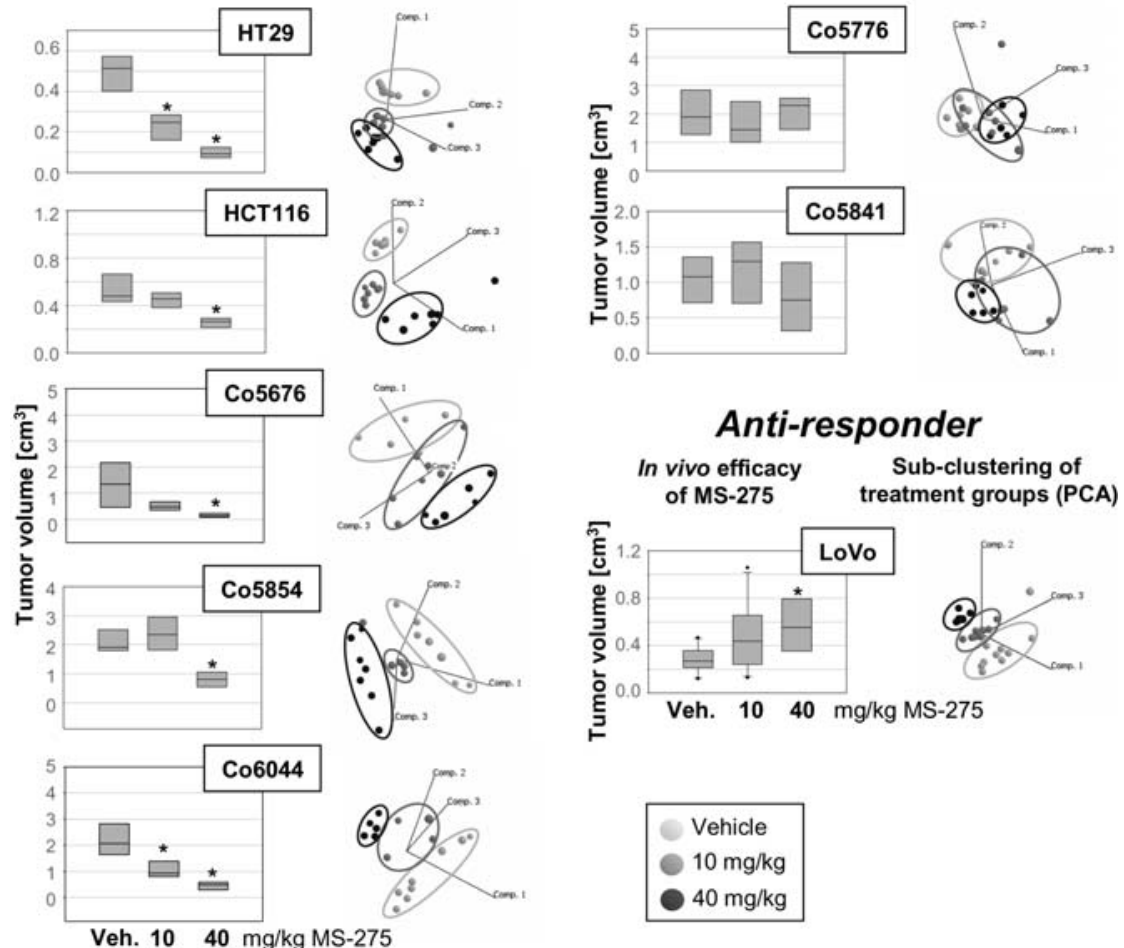

$$
\begin{array}{|l|}
\text { Vehicle } \\
10 \mathrm{mg} / \mathrm{kg} \\
40 \mathrm{mg} / \mathrm{kg}
\end{array}
$$

Figure 5. PCA of all models and correlation between MS-275 efficacy and clustering. (A) PCA clustering of all models. (B) PCA of each individual model indicates sub-clustering for treatment groups and correlation to response to MS-275 for responder and anti-responder models. The box plots show the tumor volume at the end of the experiment. The asterisk indicates a statistically significant change in tumor volume of treated animals compared to untreated ones $(\mathrm{p}<0.05)$. 
Table I. In vivo anti-tumor efficacy of MS-275 in experimental human colon carcinoma models. ${ }^{\mathrm{a}}$

\begin{tabular}{|c|c|c|c|c|c|c|}
\hline Model & Origin & $\begin{array}{l}\text { Duration of } \\
\text { experiment } \\
\text { (days) }\end{array}$ & $\begin{array}{l}\text { Median volume of } \\
\text { control tumors } \\
\left(\mathrm{cm}^{3}\right)\end{array}$ & $\begin{array}{l}\text { Median volume of } \\
\text { MS-275 treated } \\
\text { tumors }\left(\mathrm{cm}^{3}\right)\end{array}$ & $\mathrm{T} / \mathrm{C}$ & Classification \\
\hline HT29 & Cell line & 26 & 0.51 & 0.09 & 0.18 & Responder \\
\hline HCT116 & Cell line & 21 & 0.48 & 0.26 & 0.54 & Responder \\
\hline LoVo & Cell line & 58 & 0.27 & 0.55 & 2.04 & Anti-responder \\
\hline Co5676 & Tumor & 49 & 1.35 & 0.12 & 0.09 & Responder \\
\hline Co5776 & Tumor & 50 & 1.90 & 2.31 & 1.22 & Non-responder \\
\hline Co5841 & Tumor & 46 & 1.08 & 0.76 & 0.70 & Non-responder \\
\hline Co5854 & Tumor & 27 & 1.91 & 0.82 & 0.43 & Responder \\
\hline Co6044 ${ }^{\mathrm{b}}$ & Tumor & 29 & 2.07 & 0.50 & 0.24 & Responder \\
\hline
\end{tabular}

${ }^{\text {aT }}$ Tumor models were transplanted into nude mice and treated daily with $40 \mathrm{mg} / \mathrm{kg}$ MS-275. ${ }^{\mathrm{b}}$ Tumors originating from secondary liver metastatic deposits.

study revealed that some models were responders and others non-responders or even anti-responders to MS-275 treatment.

Immunoblotting experiments were then performed to determine the effects of MS-275 on HDAC2 and p21 protein levels, and on $\mathrm{H} 3$ acetylation (Fig. 4). HDAC2 expression was detected in most untreated tumors (with the exception of Co5854) and in all treated tumors. Both up- and downregulation were observed following MS-275 treatment. Concerning p21, strong re-expression was seen only in treated LoVo and HCT116 cells tumors. Hardly any signal was detected in the other tumor models. The induction of p21 did not correlate with the response to MS-275 as LoVo was an anti-responder and HCT116 a responder model. Concerning $\mathrm{H} 3$ acetylation, an increase was observed in most cases after MS-275 treatment, with the exception of Co5854 and Co6044.

Gene expression profiling - unsupervised analysis. RNA isolated from the xenograft models was subjected to global gene expression profiling in order to identify genes that were regulated by MS-275 and genes selectively regulated in responder versus non-responder tumor models (Fig. 2). Total RNA from each individual tumor was isolated, the corresponding cRNA synthesized and hybridized to a total of 169 Affymetrix HGU133Plus2.0 GeneChips. After median normalization the individual arrays were subjected to principle component analysis (PCA) to remove outliers at the expression level. Co-clustering of samples derived from each established cell line or from each colorectal cancer was visible, regardless whether the mice were treated with MS-275 or not (Fig. 5A). The three primary tumor responder models Co5841, Co5676 and Co6044 showed similar gene expression patterns in the PCA and differed from the two primary non-responder models Co5841 and Co5776. Consequently, among primary tumors, the PCA distinguished between responders and nonresponders (Fig. 5A). Altogether these results indicate that the overall gene expression patterns differed more among the models than did the expression changes induced by MS-275 treatment for each individual model.

Next, we asked whether response to MS-275 correlated with a sub-clustering of treatment groups and therefore performed PCA on each individual model (Fig. 5B). For all responder models, we observed a sub-clustering that distinguished the non-treated from the two MS-275-treated tumor groups at the gene expression level. Conversely, such a clustering was not observed in the two primary tumor models that did not respond to MS-275. The situation was different for the anti-responder model LoVo for which a dose-dependent increase in tumor growth was seen. Here, sub-clustering of the non-treated and of each treated group was observed.

Gene expression profiling - supervised analysis. Next, supervised analyses were performed to determine if MS-275 treatment led to uniform alterations of gene expression patterns. The following comparisons were performed for each model: $10 \mathrm{mg}$ MS-275 versus control, $40 \mathrm{mg}$ MS-275 versus control, 10 and $40 \mathrm{mg}$ MS-275 versus control, and 10 versus $40 \mathrm{mg}$ MS-275. For statistical analyses, we chose a Welch-test and selected regulated genes with a fold change $>5$ and a p-value $<10^{-4}$. In addition, analysis of variation $\left(\right.$ ANOVA; $\left.\mathrm{p}<10^{-5}\right)$ and K-ordered groups tests $\left(\mathrm{p}<10^{-2}\right)$ were carried out. The most significantly regulated genes in presence of $40 \mathrm{mg} / \mathrm{kg}$ MS-275 as identified with all three statistical tests are listed in Table II. This analysis showed that genes were regulated more significantly in cell line models than in primary models. Also, more genes were up- than downregulated in responder models whereas in non-responder models, most genes were down-regulated. When looking at the most significantly regulated genes in each individual model, we observed rather heterogeneous changes. The responder models HT29 and Co5854 showed a strong upregulation of genes involved in cell adhesion and cell-cell communication [for instance LGALS1 (18.8-fold) and NRCAM (90-fold)], whereas the non-responder models Co5776 and Co5841 showed a down-regulation of genes involved in cell adhesion [CLDN4 (1.6-fold) and TSPAN5 (2-fold)]. In HT29 cells, CEACAM6 and CEACAM7 were up-regulated 4- and 17.7-fold, respectively. MS-275 treatment of the HCT116 and Co5676 models led to down-regulation of cell cycle-promoting genes like TNFSF4 (20-fold), BTC 
Table II. Most significantly regulated genes in colon carcinoma xenograft models in response to $40 \mathrm{mg} / \mathrm{kg}$ MS-275. ${ }^{\text {a }}$

\begin{tabular}{|c|c|c|c|c|c|c|}
\hline \multirow[b]{2}{*}{ Model } & \multicolumn{3}{|c|}{ Up-regulated } & \multicolumn{3}{|c|}{ Down-regulated } \\
\hline & Gene symbol & Probeset ID & Fold change & Gene symbol & Probeset ID & Fold change \\
\hline \multirow[t]{3}{*}{ HT29 } & LGALS1 & 201105_at & 18.83 & AKAP7 & 205771_s_at & 0.05 \\
\hline & CEACAM7 & 206199_at & 17.66 & LGALS2 & 208450_at & 0.10 \\
\hline & PTPRO & 208121_s_at & 16.30 & MUC5AC & 214385_s_at & 0.17 \\
\hline \multirow{3}{*}{ HCT116 } & FAM49A & 209683_at & 34.51 & TNFSF4 & 207426_s_at & 0.05 \\
\hline & NGFRAP1L1 & 229963_at & 18.44 & KLRC1 & 206785_s_at & 0.10 \\
\hline & FLJ35767 & 241367_at & 10.32 & KLRC3 & 207723_s_at & 0.13 \\
\hline \multirow[t]{3}{*}{ Co 5676} & HLA-DQB1 & 212998_x_at & 13.20 & PAPSS2 & 203058_s_at & 0.43 \\
\hline & RNF182 & 230720_at & 8.14 & KPNA2 & 211762_s_at & 0.53 \\
\hline & BAMBI & 203304_at & 6.23 & HIGD1A & 221896_s_at & 0.53 \\
\hline \multirow[t]{3}{*}{ Co 5854} & NRCAM & 204105_s_at & 89.52 & AQP3 & 39248_at & 0.26 \\
\hline & TNNT1 & 213201_s_at & 35.30 & MATN2 & 202350_s_at & 0.30 \\
\hline & SCG5 & 203889_at & 20.01 & ST6GALNAC1 & 227725_at & 0.35 \\
\hline \multirow[t]{3}{*}{ Co 6044} & TNNT1 & 213201_s_at & 21.59 & TCN1 & 205513_at & 0.08 \\
\hline & TUBB2B & 214023_x_at & 14.25 & KRT6B & 213680_at & 0.17 \\
\hline & NES & 218678_at & 9.25 & CDKN1C & 213348_at & 0.20 \\
\hline \multirow[t]{3}{*}{ LoVo } & NES & 218678_at & 13.16 & FOXL1 & 243409_at & 0.20 \\
\hline & NSBP1 & 221606_s_at & 12.20 & MLPH & 218211_s_at & 0.20 \\
\hline & SCNN1A & 203453_at & 11.98 & HHIP & 237466_s_at & 0.21 \\
\hline \multirow[t]{3}{*}{ Со 5776} & NUPL1 & 204435_at & 1.58 & SLC16A1 & 1557918_s_at & 0.24 \\
\hline & RAP1GDS1 & 209444_at & 1.52 & P4HB & 200654_at & 0.57 \\
\hline & ORC4L & 203351_s_at & 1.51 & CLDN4 & 201428_at & 0.64 \\
\hline \multirow[t]{3}{*}{ Co 5841} & PSMB4 & 228204_at & 1.78 & GSN & 214040_s_at & 0.21 \\
\hline & DSG3 & 235075_at & 1.55 & RNF144 & 204040_at & 0.47 \\
\hline & IQGAP3 & 229538_s_at & 1.52 & NETO2 & 218888_s_at & 0.48 \\
\hline
\end{tabular}

${ }^{\mathrm{a}}$ Genes were selected by the overlap of three different statistical tests [Welch-test $\left(\mathrm{p}<10^{-4}\right)$, ANOVA $\left(\mathrm{p}<10^{-5}\right)$ and $\mathrm{K}$-ordered groups $\left.\left(\mathrm{p}<10^{-2}\right)\right]$, respectively.

(4.4-fold) and KPNA2 (1.9-fold). In the non- and antiresponder models Co5776, Co5841 and LoVo, genes involved in the regulation of transcription were up-regulated [NSBP1 (12.2-fold), GTF2H1 (1.4-fold) and EZH2 (1.4-fold)] or down-regulated [FOXL1 (5-fold) and GLIS3 (3.1-fold)]. Interestingly, gelsolin (GSN) was down-regulated 4.8-fold in the Co5841 model.

As we did not observe a strong overlap of regulated genes between the five responder models, we used less stringent criteria. We called for a significant change in the expression level in at least two of the three statistical tests. With this new setting we identified 116 up- and 43 down-regulated genes after MS-275 treatment that exhibited a dose-dependent regulation in at least 4 out of 5 responder models. Interestingly, 34 of these genes showed up-regulation in all responders and down-regulation or no change of regulation in at least 2 out of 3 non-responders, whereas 13 genes exhibited downregulation in all responders and up-regulation or no change in at least two out of three non-responders (Table III). These genes may serve as biomarkers to predict the response to MS-275.
Confirmation of microarray data by quantitative real-time $R T-P C R$. The three most significantly regulated genes showing up-regulation in most responder models but not in nonresponder models were those coding for PRA1, MYADM and PALM2-AKAP2 (Fig. 6A). Quantitative real-time PCR was performed to confirm these findings. Total RNA was extracted from each treatment group for each model. The normalized gene expression levels in treated tumors relative to the expression in untreated tumors are shown in Fig. 6B. The quantitative real-time PCR analysis confirmed the upregulation of these three genes in at least four of the five responder models and the down-regulation or no change in at least 2 of the 3 non-responder models. However, in the LoVo model, the absence of up-regulation of PRA1 and MYADM could not been confirmed by quantitative real-time RT-PCR.

Pathway analysis. To gain a deeper insight into the mechanisms of action of MS-275, we performed a pathway analysis using the GeneGo Metacore database and software (Fig. 7). Genes regulated by MS-275 treatment as compared 
A

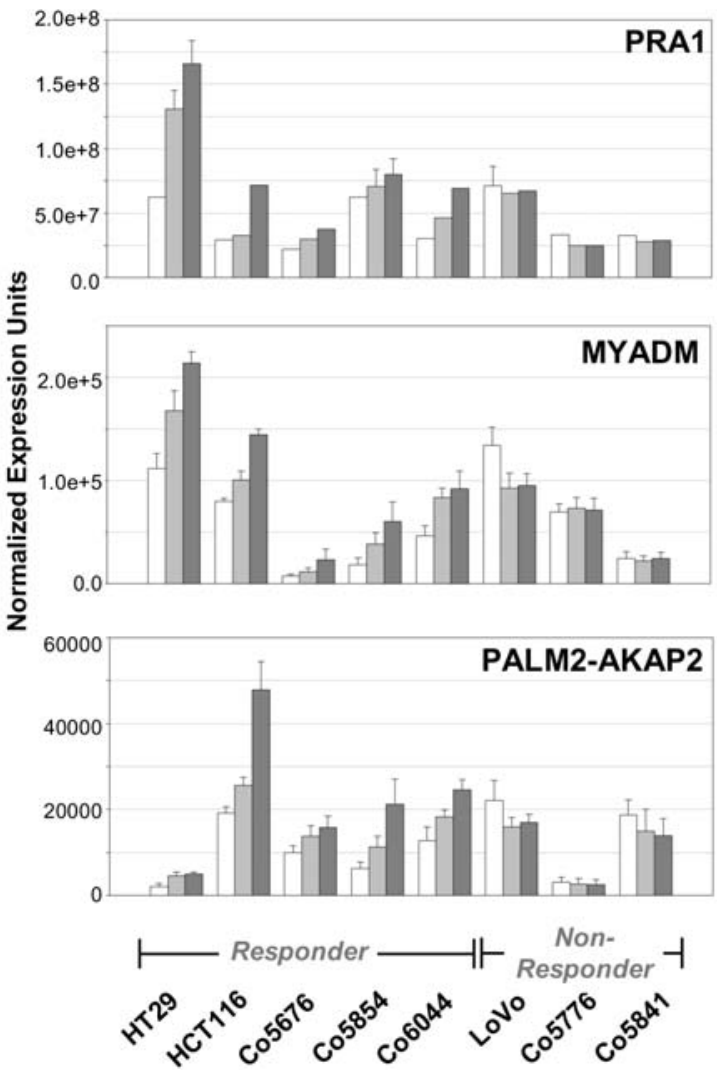

B

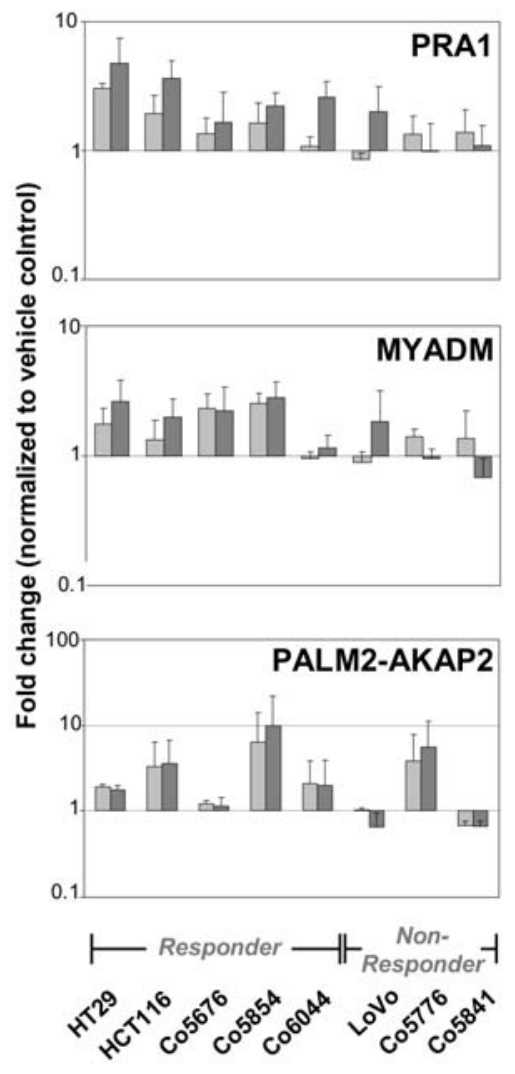

Figure 6. Examples of genes regulated upon MS-275 treatment. Genes were selected by the overlap of 2 out of 3 statistical tests [Welch-test (p<10-4), ANOVA $\left(\mathrm{p}<10^{-5}\right)$ and K-ordered groups tests $\left.\left(\mathrm{p}<10^{-2}\right)\right]$. (A) Normalized expression of three selected genes showing an up-regulation in responder but not in non-responder or anti-responder models. Normalized expression levels for control (white columns), $10 \mathrm{mg} / \mathrm{kg} \mathrm{MS}-275$ (light grey columns) and $40 \mathrm{mg} / \mathrm{kg}$ MS-275 (dark grey columns) are shown. (B) Confirmation of expression changes of selected genes by quantitative real-time PCR of pooled RNA from each tumor and treatment group. Fold changes normalized to vehicle control are shown in light grey columns (10 mg/kg MS-275) and dark grey columns (40 mg/kg MS-275). Mean values \pm SD of three independent real-time PCR runs are shown.

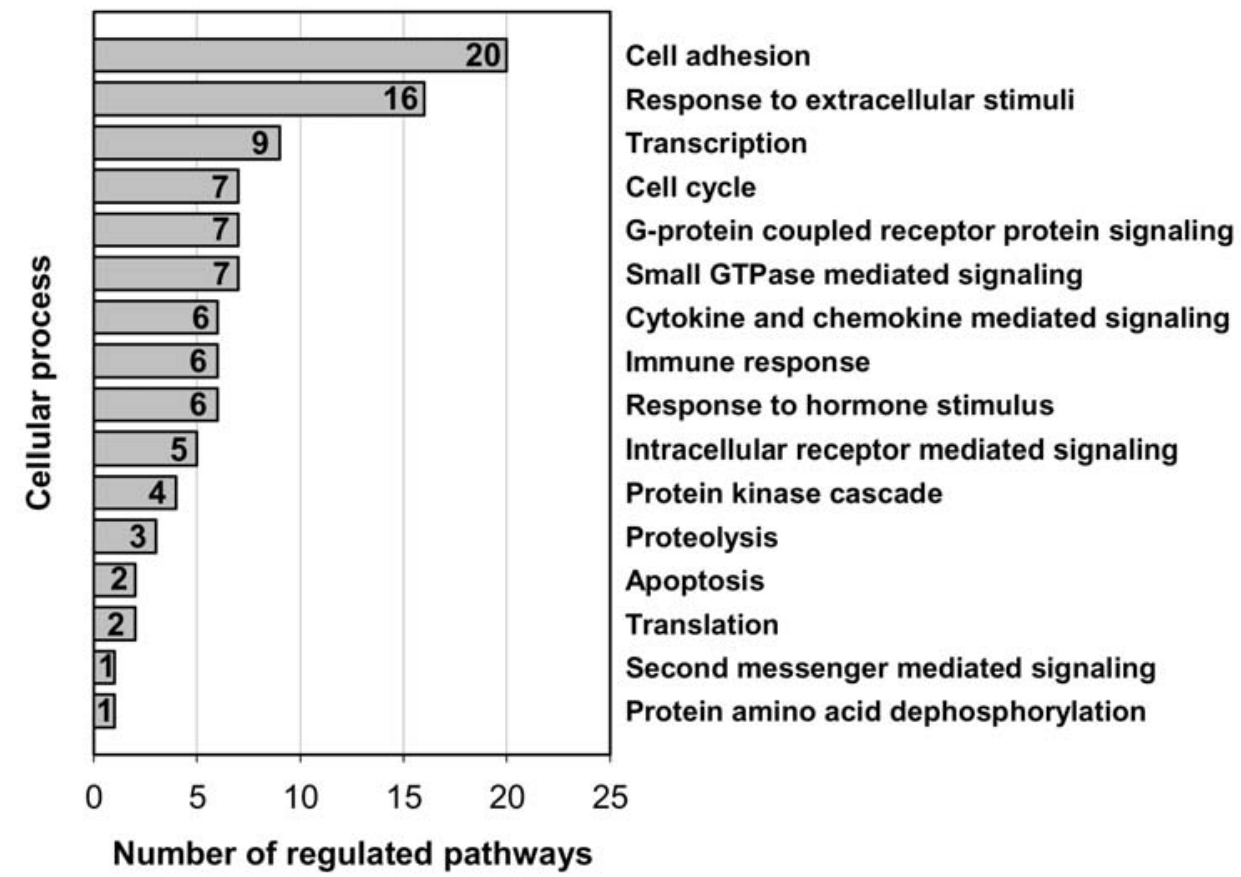

Figure 7. The pathways most significantly regulated after MS-275 treatment (40 mg/kg) were categorized using the GeneGO Metacore database according to their involvement in cellular processes. One pathway can be a member of more than one process. 
Table III. Oppositely regulated genes in responder and non-responder models following treatment with $40 \mathrm{mg} / \mathrm{kg}$ MS-275.

\begin{tabular}{|c|c|c|c|c|c|c|c|c|c|c|c|}
\hline Gene symbol & Probeset ID & \multicolumn{5}{|c|}{ Responders } & \multicolumn{3}{|c|}{ Non-responders } & $\begin{array}{l}\text { Up in } \\
\text { responders }\end{array}$ & $\begin{array}{c}\text { Down or } \\
\text { no change in } \\
\text { non-responders }\end{array}$ \\
\hline \multicolumn{12}{|l|}{ PALM2- } \\
\hline AKAP2 & 202760_s_at & 2.4 & 2.5 & 1.6 & 3.4 & 1.9 & 0.8 & 0.8 & 0.7 & $5 / 5$ & $3 / 3$ \\
\hline OAT & 201599_at & 1.3 & 1.4 & 1.2 & 1.2 & 2.6 & 0.9 & 1.0 & 0.8 & $5 / 5$ & $3 / 3$ \\
\hline PRSS23 & 202458_at & 1.0 & 2.4 & 2.0 & 1.6 & 1.3 & 0.4 & 0.8 & 0.8 & $5 / 5$ & $3 / 3$ \\
\hline C20orf3 & 206656_s_at & 1.4 & 1.8 & 1.5 & 1.3 & 1.3 & 0.9 & 0.9 & 1.0 & $5 / 5$ & $3 / 3$ \\
\hline MYADM & 225673_at & 1.9 & 1.8 & 3.2 & 3.3 & 2.0 & 0.7 & 1.0 & 1.0 & $5 / 5$ & $3 / 3$ \\
\hline SH3KBP1 & 223082_at & 1.8 & 1.2 & 1.6 & 1.1 & 1.5 & 0.8 & 0.9 & 1.0 & $5 / 5$ & $3 / 3$ \\
\hline 56400823 & 225809_at & 3.4 & 2.3 & 1.7 & 1.9 & 2.1 & 1.4 & 0.7 & 0.9 & $5 / 5$ & $2 / 3$ \\
\hline LITAF & 200706_s_at & 1.5 & 1.9 & 1.4 & 1.3 & 1.6 & 1.1 & 0.9 & 0.9 & $5 / 5$ & $2 / 3$ \\
\hline NSMCE1 & 224666_at & 1.4 & 1.1 & 1.2 & 1.6 & 1.7 & 0.9 & 1.1 & 1.0 & $5 / 5$ & $2 / 3$ \\
\hline
\end{tabular}

$\mathrm{B}, \log 2$ ratio vehicle control versus $40 \mathrm{mg} / \mathrm{kg} \mathrm{MS}-275$

\begin{tabular}{|c|c|c|c|c|c|c|c|c|c|c|c|}
\hline \multirow[b]{2}{*}{ Gene symbol } & \multirow[b]{2}{*}{ Probeset ID } & \multicolumn{5}{|c|}{ Responders } & \multicolumn{3}{|c|}{ Non-responders } & \multirow{2}{*}{$\begin{array}{l}\text { Down in } \\
\text { responders }\end{array}$} & \multirow{2}{*}{$\begin{array}{c}\text { Up or } \\
\text { no change in } \\
\text { non-responders }\end{array}$} \\
\hline & & HT29 & HCT116 & Co5676 & Co5854 & Co6044 & LoVo & Co5776 & Co5841 & & \\
\hline BAZ1A & 217986_s_at & 0.6 & 0.6 & 0.8 & 0.9 & 1.0 & 1.2 & 1.1 & 1.1 & $5 / 5$ & $3 / 3$ \\
\hline LACTB2 & 222714_s_at & 0.5 & 0.9 & 0.5 & 0.8 & 0.6 & 1.8 & 1.0 & 1.0 & $5 / 5$ & $3 / 3$ \\
\hline FLJ21345 fis & 234219_at & 0.7 & 0.9 & 0.4 & 1.0 & 0.4 & 1.5 & 1.0 & 1.0 & $5 / 5$ & $3 / 3$ \\
\hline C6orf51 & 225083_at & 0.5 & 0.4 & 0.8 & 0.6 & 0.5 & 0.9 & 1.2 & 1.0 & $5 / 5$ & $2 / 3$ \\
\hline HMGN2 & 208668_x_at & 0.8 & 0.6 & 0.6 & 0.8 & 0.9 & 0.9 & 1.1 & 1.1 & $5 / 5$ & $2 / 3$ \\
\hline HSPC268 & 226780_s_at & 0.6 & 0.6 & 0.5 & 0.5 & 0.7 & 0.9 & 1.0 & 1.1 & $5 / 5$ & $2 / 3$ \\
\hline LOC644246 & 230388_s_at & 0.5 & 0.9 & 0.7 & 0.7 & 0.6 & 0.8 & 1.2 & 1.2 & $5 / 5$ & $2 / 3$ \\
\hline ADI1 & 217761_at & 0.4 & 0.5 & 0.6 & 0.6 & 0.7 & 0.4 & 1.0 & 1.2 & $5 / 5$ & $2 / 3$ \\
\hline TRMT5 & 221952_x_at & 0.7 & 0.5 & 0.5 & 0.8 & 0.8 & 0.9 & 1.1 & 1.1 & $5 / 5$ & $2 / 3$ \\
\hline
\end{tabular}

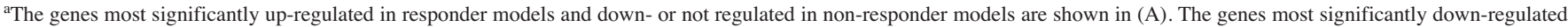
in responder models and up- or not regulated in non-responder models are shown in (B). The ratio refers to the comparison of the $40 \mathrm{mg} / \mathrm{kg}$ and the vehicle control group. Genes were selected by the overlap of two of three different statistical tests (either Welch-test, $\mathrm{p}<10^{-4}$ or ANOVA, $\mathrm{p}<10^{-5}$ and $\mathrm{K}$-ordered groups, $\mathrm{p}<10^{-2}$ ).

to the corresponding control groups were submitted to pathway analysis. Affected pathways were sorted according to the total number of affected genes and the significance of the regulation ( $\mathrm{p}$-value). The 100 most significantly regulated pathways were categorized according to the cellular processes they affected $(\mathrm{p}<0.017)$. This revealed that the most perturbed cellular processes following MS-275 treatment were cell adhesion, response to extracellular stimuli and transcription.

\section{Discussion}

This study was devised to examine the anti-tumor effects of MS-275 in in vitro and in vivo models of human colorectal cancer. MS-275 is a potent HDAC inhibitor with selectivity for the class I family members $(28,35-37)$. Treatment of five colon cancer cell lines with MS-275 at a sub $\mathrm{IC}_{50}$ concentration revealed that efficacy did not correlate with changes in previously described pharmacodynamic markers such as p21 expression or $\mathrm{H} 3$ and $\mathrm{H} 4$ acetylation. However, the expression of HDAC2 in the cell lines correlated best with MS-275 efficacy in vitro. In line with this, HDAC2 knock-down resulted in a partial abrogation of the anti-proliferative potency of the compound. These results are consistent with previously published ones reporting that loss of HDAC2 expression and activity in sporadic cancers rendered them resistant to the HDAC inhibitor TSA (41). Transfection of wild-type HDAC2 into the HDAC2-deficient colon cell line RKO restored TSA sensitivity (41). We found that the five colon cancer cell lines, as well as the eight xenograft models expressed full-length HDAC2. This isoform is therefore likely to be responsible for at least some of the anti-proliferative effects we observed. On the other hand, the fact that nearly complete elimination of HDAC2 did not entirely obliterate the antiproliferative effect of the compound strongly suggests that additional cellular targets might be involved in the anti-tumor effects of MS-275.

Predicting the efficacy of MS-275 in vitro can therefore not solely be based upon examination of a single marker. 
Only the combined examination of the above-mentioned markers, and probably of even more, will allow the prediction of the efficacy of MS-275. Strong p21 induction as well as HDAC2 expression combined with strong and early $\mathrm{H} 3$ and H4 hyperacetylation, as seen in HCT116 cells, correlated with good response. The same holds true for the interpretation of these markers in vivo. We did not observe that HDAC inhibition led to $\mathrm{H} 3$ and $\mathrm{H} 4$ hyperacetylation and p21 induction of expression, the claimed hallmarks of HDAC inhibition, in all tested in vivo models of colon cancer. These changes can thus not be ascribed to every model of human cancer and every HDAC inhibitor. Our systematic analysis of different xenograft models as well as the in vitro analysis of five different colon cancer cell lines showed that there was a need for new, more sensitive and reliable biomarkers to predict the response and sensitivity of tumors to the treatment with MS-275.

We therefore performed microarray analyses of eight colon cancer xenograft models to learn more about the mode of action of MS-275 and to find markers that may help to distinguish between MS-275 responders and non-responders. The present study revealed a rather non-uniform response towards MS-275 treatment, which reflected the molecular heterogeneity of the xenograft models used. We did not see a correlation between the different types of xenograft models, either derived from established cell lines or colorectal cancer, and the response towards MS-275. We identified two responder cell lines (HT29 and HCT116) and one anti-responder (LoVo), two responder primary models (Co5854 and Co5676) and one nonresponder (Co5776), as well as one metastasis model responder (Co6044) and one non-responder (Co5841). The gene expression profiles of these models were rather heterogeneous and the PCA revealed more differences among individual models than among treatment groups.

With the help of stringent statistical tests, we identified a number of potential biomarkers for MS-275. These markers were up-regulated dose-dependently upon MS-275 treatment in the five responder models and showed no induction in the three non-responder models. PRA1 is a ubiquitous protein which binds to prenylated Rab GTPases (42). Its overexpression impairs TCF/ß-catenin signaling, which plays a prominent role in colon cancer, possibly by limiting nuclear translocation of $\beta$-catenin (43). This was linked to ERK1/2 dephosphorylation. Re-expression of PRA1 upon MS-275 treatment may therefore lead to inhibition of the TCF/ß-catenin pathway by blockade of the nuclear translocation and thus prevention of the transcriptional stimulation of genes involved in tumor formation and proliferation. MYADM is associated with the differentiation of hematopoietic and acute promyeolocytic leukemia cells $(44,45)$. All-trans retinoic acid treatment induces expression of this differentiation marker in NB4 cells. The up-regulation of this gene upon MS-275 treatment may reflect the potential of the compound to induce differentiation in tumor cells and could serve as a differentiation and response biomarker for MS-275. Little is known about PALM2-AKAP2 (46). The corresponding mRNA is a naturally occurring cotranscribed product of the adjacent PALM2 and AKAP2 genes but the significance of this co-transcribed mRNA and the function of its putative protein product have not yet been determined.

A comparison of expression profiles of different HDAC inhibitors revealed a very small overlap of regulated genes, pointing out the importance of specific studies for each HDAC inhibitor when it comes to evaluating and validating stratification biomarkers. We studied the effects of MS-275 in eight different systems and found the overlap between regulated genes to be rather small, suggesting that each model carried individual patterns of epigenetic marks that contribute to their differential gene expression and response to treatment.

Pathway analysis revealed that MS-275 strongly affected cell adhesion pathways. Among the 100 most significantly affected pathways, 20 were involved in the regulation of cellcell adhesion, communication, motility, or tumor invasion. Several cell adhesion genes were up-regulated in MS-275 responder models but down-regulated in non-responder models. In the HT29 and HCT116 models many integrins and tetraspanins, such as 31 -integrin, CD9 or CD81, were up-regulated, whereas these genes were down-regulated in Co5841, Co5776 and LoVo. Besides that, E-cadherin, an important suppressor of epithelial tumor cell invasiveness and metastasis which is epigenetically silenced through promoter methylation in many carcinomas (47), was downregulated in the non-responder models Co5841 and Co5776 upon MS-275 treatment. This implies that MS-275 did not induce the re-expression of E-cadherin, but rather promoted the hypermethylated status of the primary non-responder models. E-Cadherin as well as claudin 4 (CLDN4), which were down-regulated in Co5776, are decreased in diffuse type and poorly differentiated tumors $(47,48)$. Dysfunction of these proteins may therefore play a role in disruption of cellcell adhesion. In conclusion, MS-275 might increase the adhesive properties of tumor cells in responder models thus preventing the metastatic spread and the immune escape of the malignant cells, whereas in non-responder models most cell adhesion molecules were down-regulated.

Taken together, the different in vitro and in vivo effects of MS-275 as well as the expression changes induced in responder and non-responder models revealed the pleiotropic effects of this compound on different cellular pathways affecting tumors and their microenvironment.

\section{Acknowledgements}

The excellent contributions of our technical assistants Nicole Kelm, Bianca Timpner, Karola Henschel and Anja Klinner are gratefully acknowledged. We also thank all other internal and external colleagues who supported this project. This work was supported by EPITRON, an Integrated Project funded by the European Union under the 6th Framework Programme (LSHC-CT-2005-518417).

\section{References}

1. Oki Y and Issa JP: Review: recent clinical trials in epigenetic therapy. Rev Recent Clin Trials 1: 169-182, 2006.

2. Baylin SB and Ohm JE: Epigenetic gene silencing in cancer - a mechanism for early oncogenic pathway addiction? Nat Rev Cancer 6: 107-116, 2006.

3. Kubicek S, Schotta G, Lachner M, Sengupta R, Kohlmaier A, Perez-Burgos L, Linderson Y, Martens JH, O'Sullivan RJ, Fodor BD, Yonezawa M, Peters AH and Jenuwein T: The role of histone modifications in epigenetic transitions during normal and perturbed development. Ernst Schering Res Found Workshop 57: 1-27, 2006.

4. Esteller M: Cancer epigenomics: DNA methylomes and histonemodification maps. Nat Rev Genet 8: 286-298, 2007. 
5. Wang GG, Allis CD and Chi P: Chromatin remodeling and cancer, Part I: Covalent histone modifications. Trends Mol Med 13: 363-372, 2007

6. Goldberg AD, Allis CD and Bernstein E: Epigenetics: a landscape takes shape. Cell 128: 635-638, 2007.

7. Kouzarides T: Chromatin modifications and their function. Cell 128: 693-705, 2007

8. Esteller M: Epigenetic gene silencing in cancer: the DNA hypermethylome. Hum Mol Genet 16 (Spec No 1): R50-R59, 2007.

9. Agger K, Christensen J, Cloos PA and Helin K: The emerging functions of histone demethylases. Curr Opin Genet Dev 18 159-168, 2008.

10. Yang XJ and Seto E: Lysine acetylation: codified crosstalk with other posttranslational modifications. Mol Cell 31: 449-461, 2008.

11. Abreu PA, Dellamora-Ortiz G, Leao-Ferreira LR, Gouveia M, Braggio E, Zalcberg I, Santos DO, Bourguinhon S, Cabral LM, Rodrigues CR and Castro HC: DNA methylation: a promising target for the twenty-first century. Expert Opin Ther Targets 12: 1035-1047, 2008.

12. Glozak MA and Seto E: Histone deacetylases and cancer. Oncogene 26: 5420-5432, 2007.

13. Mottet D and Castronovo V: Histone deacetylases: target enzymes for cancer therapy. Clin Exp Metastasis 25: 183-189, 2008.

14. Johnstone RW: Histone-deacetylase inhibitors: novel drugs for the treatment of cancer. Nat Rev Drug Discov 1: 287-299, 2002.

15. Pan LN, Lu J and Huang B: HDAC inhibitors: a potential new category of anti-tumor agents. Cell Mol Immunol 4: 337-343, 2007.

16. Wang LG, Liu XM, Fang Y, Dai W, Chiao FB, Puccio GM, Feng J, Liu D and Chiao JW: De-repression of the p21 promoter in prostate cancer cells by an isothiocyanate via inhibition of HDACs and c-Myc. Int J Oncol 33: 375-380, 2008.

17. Bruserud O, Stapnes C, Ersvaer E, Gjertsen BT and Ryningen A: Histone deacetylase inhibitors in cancer treatment: a review of the clinical toxicity and the modulation of gene expression in cancer cell. Curr Pharm Biotechnol 8: 388-400, 2007.

18. Perez-Balado C, Nebbioso A, Rodriguez-Grana P, Minichiello A, Miceli M, Altucci L and de Lera AR: Bispyridinium dienes: histone deacetylase inhibitors with selective activities. J Med Chem 50: 2497-2505, 2007

19. Huang BH, Laban M, Leung CH, Lee L, Lee CK, Salto-Tellez M, Raju GC and Hooi SC: Inhibition of histone deacetylase 2 increases apoptosis and p21Cip1/WAF1 expression, independent of histone deacetylase 1. Cell Death Differ 12: 395-404, 2005

20. Ocker M and Schneider-Stock R: Histone deacetylase inhibitors: signalling towards p21cip1/waf1. Int J Biochem Cell Biol 39: $1367-1374,2007$

21. Hoshino I, Matsubara H, Akutsu Y, Nishimori T, Yoneyama Y, Murakami K, Komatsu A, Sakata H, Matsushita K and Ochiai T: Gene expression profiling induced by histone deacetylase inhibitor, FK228, in human esophageal squamous cancer cells. Oncol Rep 18: 585-592, 2007

22. Glaser KB, Staver MJ, Waring JF, Stender J, Ulrich RG and Davidsen SK: Gene expression profiling of multiple histone deacetylase (HDAC) inhibitors: defining a common gene set produced by HDAC inhibition in T24 and MDA carcinoma cell lines. Mol Cancer Ther 2: 151-163, 2003.

23. Chiba T, Yokosuka O, Fukai K, Kojima H, Tada M, Arai M, Imazeki $\mathrm{F}$ and Saisho $\mathrm{H}$ : Cell growth inhibition and gene expression induced by the histone deacetylase inhibitor, trichostatin A, on human hepatoma cells. Oncology 66: 481-491, 2004.

24. Milutinovic S, D'Alessio AC, Detich N and Szyf M: Valproate induces widespread epigenetic reprogramming which involves demethylation of specific genes. Carcinogenesis 28: 560-571, 2007

25. Tavares TS, Nanus D, Yang XJ and Gudas LJ: Gene microarray analysis of human renal cell carcinoma: the effects of HDAC inhibition and retinoid treatment. Cancer Biol Ther 7. 2008.

26. Glozak MA, Sengupta N, Zhang X and Seto E: Acetylation and deacetylation of non-histone proteins. Gene 363: 15-23, 2005.

27. Faus $\mathrm{H}$ and Haendler B: Post-translational modifications of steroid receptors. Biomed Pharmacother 60: 520-528, 2006.

28. Hu E, Dul E, Sung CM, Chen Z, Kirkpatrick R, Zhang GF, Johanson K, Liu R, Lago A, Hofmann G, Macarron R, De los Frailes M, Perez P, Krawiec J, Winkler J and Jaye M: Identification of novel isoform-selective inhibitors within class I histone deacetylases. J Pharmacol Exp Ther 307: 720-728, 2003.

29. Inoue S, Mai A, Dyer MJ and Cohen GM: Inhibition of histone deacetylase class I but not class II is critical for the sensitization of leukemic cells to tumor necrosis factor-related apoptosisinducing ligand-induced apoptosis. Cancer Res 66: 6785-6792, 2006
30. Moradei O, Vaisburg A and Martell RE: Histone deacetylase inhibitors in cancer therapy: new compounds and clinical update of benzamide-type agents. Curr Top Med Chem 8: 841-858, 2008.

31. Beckers T, Burkhardt C, Wieland H, Gimmnich P, Ciossek T, Maier T and Sanders K: Distinct pharmacological properties of second generation HDAC inhibitors with the benzamide or hydroxamate head group. Int J Cancer 121: 1138-1148, 2007.

32. Khan N, Jeffers M, Kumar S, Hackett C, Boldog F, Khramtsov N, Qian X, Mills E, Berghs SC, Carey N, Finn PW, Collins LS, Tumber A, Ritchie JW, Jensen PB, Lichenstein HS and Sehested M: Determination of the class and isoform selectivity of small-molecule histone deacetylase inhibitors. Biochem J 409: 581-589, 2008.

33. Xu WS, Parmigiani RB and Marks PA: Histone deacetylase inhibitors: molecular mechanisms of action. Oncogene 26: 5541-5552, 2007

34. Bolden JE, Peart MJ and Johnstone RW: Anticancer activities of histone deacetylase inhibitors. Nat Rev Drug Discov 5: 769-784, 2006.

35. Hess-Stumpp H, Bracker TU, Henderson D and Politz O: MS275 , a potent orally available inhibitor of histone deacetylasesthe development of an anticancer agent. Int J Biochem Cell Biol 39: 1388-1405, 2007

36. Rosato RR, Almenara JA and Grant S: The histone deacetylase inhibitor MS-275 promotes differentiation or apoptosis in human leukemia cells through a process regulated by generation of reactive oxygen species and induction of p21CIP1/WAF1 1 . Cancer Res 63: 3637-3645, 2003.

37. Saito A, Yamashita T, Mariko Y, Nosaka Y, Tsuchiya K, Ando T, Suzuki T, Tsuruo T and Nakanishi O: A synthetic inhibitor of histone deacetylase, MS-27-275, with marked in vivo antitumor activity against human tumors. Proc Natl Acad Sci USA 96: 4592-4597, 1999.

38. Kondo Y and Issa JP: Epigenetic changes in colorectal cancer. Cancer Metastasis Rev 23: 29-39, 2004.

39. Zhu P, Martin E, Mengwasser J, Schlag P, Janssen KP and Gottlicher M: Induction of HDAC2 expression upon loss of APC in colorectal tumorigenesis. Cancer Cell 5: 455-463, 2004.

40. Fichtner I, Slisow W, Gill J, Becker M, Elbe B, Hillebrand T and Bibby M: Anticancer drug response and expression of molecular markers in early-passage xenotransplanted colon carcinomas. Eur J Cancer 40: 298-307, 2004.

41. Ropero S, Fraga MF, Ballestar E, Hamelin R, Yamamoto H, Boix-Chornet M, Caballero R, Alaminos M, Setien F, Paz MF, Herranz M, Palacios J, Arango D, Orntoft TF, Aaltonen LA, Schwartz S, Jr and Esteller M: A truncating mutation of HDAC2 in human cancers confers resistance to histone deacetylase inhibition. Nat Genet 38: 566-569, 2006.

42. Gougeon PY, Prosser DC, Da-Silva LF and Ngsee JK: Disruption of Golgi morphology and trafficking in cells expressing mutant prenylated rab acceptor-1. J Biol Chem 277: 36408-36414, 2002.

43. Kim JT, Cho MY, Choi SC, Kim JW, Chae SK, Yoon DY, Kim JW and Lim JS: Prenylated Rab acceptor 1 (PRA1) inhibits TCF/ beta-catenin signaling by binding to beta-catenin. Biochem Biophys Res Commun 349: 200-208, 2006.

44. Cui W, Yu L, He H, Chu Y, Gao J, Wan B, Tang L and Zhao S: Cloning of human myeloid-associated differentiation marker (MYADM) gene whose expression was up-regulated in NB4 cells induced by all-trans retinoic acid. Mol Biol Rep 28: 123-138, 2001.

45. Wang Q, Li N, Wang X, Shen J, Hong X, Yu H, Zhang Y, Wan T, Zhang L, Wang J and Cao X: Membrane protein hMYADM preferentially expressed in myeloid cells is up-regulated during differentiation of stem cells and myeloid leukemia cells. Life Sci 80: 420-429, 2007.

46. Hu B, Copeland NG, Gilbert DJ, Jenkins NA and Kilimann MW: The paralemmin protein family: identification of paralemmin-2, an isoform differentially spliced to AKAP2/AKAP-KL, and of palmdelphin, a more distant cytosolic relative. Biochem Biophys Res Commun 285: 1369-1376, 2001.

47. Reinhold WC, Reimers MA, Maunakea AK, Kim S, Lababidi S, Scherf U, Shankavaram UT, Ziegler MS, Stewart C, KourosMehr H, Cui H, Dolginow D, Scudiero DA, Pommier YG, Munroe DJ, Feinberg AP and Weinstein JN: Detailed DNA methylation profiles of the E-cadherin promoter in the NCI-60 cancer cells. Mol Cancer Ther 6: 391-403, 2007.

48. Michl P, Barth C, Buchholz M, Lerch MM, Rolke M, Holzmann KH, Menke A, Fensterer H, Giehl K, Lohr M, Leder G, Iwamura T, Adler $\mathrm{G}$ and Gress TM: Claudin-4 expression decreases invasiveness and metastatic potential of pancreatic cancer. Cancer Res 63: 6265-6271, 2003 